\title{
Broaching probability for a ship in irregular stern-quartering waves: theoretical prediction and experimental validation
}

\author{
Naoya Umeda ${ }^{1} \cdot$ Satoshi Usada $^{1} \cdot$ Kentaro Mizumoto $^{1} \cdot$ Akihiko Matsuda $^{2}$
}

Received: 5 October 2015/ Accepted: 24 December 2015/Published online: 29 January 2016

(C) The Author(s) 2016. This article is published with open access at Springerlink.com

\begin{abstract}
To avoid stability failure due to the broaching associated with surf riding, the International Maritime Organization (IMO) has begun to develop multilayered intact stability criteria. A theoretical model using deterministic ship dynamics and stochastic wave theory is a candidate for the highest layer of this scheme. To complete the project, experimental validation of the theoretical method for estimating broaching probability in irregular waves is indispensable. We therefore conducted free-running model experiments using a typical twin-propeller and twin-rudder ship in irregular waves. A simulation model of coupled surge-sway-yaw-roll motion was simultaneously refined. The broaching probability calculated by the theoretical method was within the $95 \%$ confidence interval of that obtained from the experimental data. This could be an example of experimental validation of the theoretical method for estimating the broaching probability when a ship meets a wave.
\end{abstract}

Keywords IMO $\cdot$ Second-generation intact stability criteria $\cdot$ Surf riding $\cdot$ Free-running model experiment

\section{List of symbols \\ $a_{H} \quad$ Rudder force increase factor \\ $A_{R} \quad$ Rudder area \\ $B \quad$ Ship breadth \\ $B(x) \quad$ Breadth of each section}

Naoya Umeda

umeda@naoe.eng.osaka-u.ac.jp

1 Department of Naval Architecture and Ocean Engineering, Graduate School of Engineering, Osaka University, 2-1,

Yamadaoka, Suita, Osaka 565-0971, Japan

2 National Research Institute of Fisheries Engineering, 620-7, Hasaki, Kamisu 314-0408, Ibaraki, Japan c Wave celerity

$C \quad$ Binomial indicator of occurrence of broaching

$C_{b} \quad$ Block coefficient

$C_{T} \quad$ Total resistance coefficient

$D \quad$ Ship depth

d Ship draft

$d(x) \quad$ Draft of each section

$D_{P} \quad$ Propeller diameter

$F_{n} \quad$ Nominal Froude number

$g \quad$ Gravitational acceleration

GM Metacentric height

GZ Righting arm

$H \quad$ Wave height

$I_{x x} \quad$ Moment of inertia in roll

$I_{z z} \quad$ Moment of inertia in yaw

$J_{x x} \quad$ Added moment of inertia in roll

$J_{z z} \quad$ Added moment of inertia in yaw

$k \quad$ Wave number

$K_{\dot{\varphi}} \quad$ Derivative of roll moment with respect to roll rate

$K_{r} \quad$ Derivative of roll moment with respect to yaw rate

$K_{P} \quad$ Rudder gain

$K_{T} \quad$ Thrust coefficient of propeller

$K_{v} \quad$ Derivative of roll moment with respect to sway velocity

$K_{W} \quad$ Wave-induced roll moment

$K_{R} \quad$ Rudder-induced roll moment

$K_{\varphi} \quad$ Derivative of roll moment with respect to roll angle

$L \quad$ Ship length between perpendiculars

$l \quad$ Local wavelength to ship length ratio

$l_{R}{ }^{\prime} \quad$ Correction factor for flow straightening due to yaw

$m \quad$ Ship mass 
$m_{x} \quad$ Added mass in surge

$m_{y} \quad$ Added mass in sway

$n \quad$ Propeller revolution number

$N_{r} \quad$ Derivative of yaw moment with respect to yaw rate

$N_{T} \quad$ Yaw moment due to twin propellers

$N_{v} \quad$ Derivative of yaw moment with respect to sway velocity

$N_{W} \quad$ Wave-induced yaw moment

$N_{R} \quad$ Rudder-induced yaw moment

$N_{\varphi} \quad$ Derivative of yaw moment with respect to roll angle

p Roll rate

$r \quad$ Yaw rate

$R \quad$ Ship resistance

$s \quad$ Local wave steepness

$S \quad$ Broaching zone

$S_{F} \quad$ Wetted hull surface area

$S_{P} \quad$ Submerged disc area of portside propeller

$S_{S} \quad$ Submerged disc area of starboard propeller

$S_{\infty} \quad$ Propeller disc area

$S(x) \quad$ Area of each section

$S_{y}(x) \quad$ Added mass of each section in sway

$S_{y} l_{n}(x)$ Added moment of each section in sway

$t \quad$ Time

$t_{p} \quad$ Thrust deduction factor

$T \quad$ Propeller thrust

$T_{D} \quad$ Time constant for differential control

$T_{E} \quad$ Time constant for steering gear

$T_{\varphi} \quad$ Natural roll period

$u \quad$ Surge velocity

$U \quad$ Ship speed

$v \quad$ Sway velocity

$W \quad$ Ship displacement

$w_{p} \quad$ Effective propeller wake fraction

$x_{H R} \quad$ Longitudinal position of additional lateral force due to rudder

$x_{R} \quad$ Longitudinal position of rudder

$x_{P} \quad$ Longitudinal position of propeller

$X_{W} \quad$ Wave-induced surge force

$y_{P P} \quad$ Horizontal position of port-side propeller

$y_{P S} \quad$ Horizontal position of starboard-side propeller

$Y_{r} \quad$ Derivative of sway force with respect to yaw rate

$Y_{v} \quad$ Derivative of sway force with respect to sway velocity

$Y_{W} \quad$ Wave-induced sway force

$Y_{R} \quad$ Rudder-induced sway force

$Y_{\varphi} \quad$ Derivative of sway force with respect to roll angle

$z_{H} \quad$ Vertical position of center of sway force due to lateral motion

$\delta \quad$ Rudder angle

$\delta_{\max } \quad$ Maximum rudder angle

$\gamma_{R} \quad$ Flow-straightening effect coefficient $\varepsilon$

$\zeta_{a} \quad$ Wave amplitude

$\zeta_{p p} \quad$ Elevation of port propeller

$\zeta_{p s}$

$\zeta_{W r}$

$\theta$

$\kappa$

$\kappa_{P}$

$\lambda$

$\Lambda_{R}$

$\rho$

$\varphi$

$\chi$

$\chi_{C}$

Relative wave elevation

Pitch angle

Radius of longitudinal gyration

Wavelength

Rudder aspect ratio

Water density

Roll angle

Propeller-induced flow velocity factor

Heading angle from wave direction

Desired heading angle from wave direction

\section{Introduction}

Broaching is a phenomenon in which a ship cannot maintain a constant course despite the maximum steering effort being applied. Broaching often occurs when a ship is surf ridden on the downslope of a stern-quartering wave, which induces significant yaw moment. The centrifugal forces resulting from this violent yaw motion can result in capsizing. This presents a real threat to high-speed vessels such as destroyers, high-speed RoPax ferries, and fishing vessels.

To prevent stability failure due to the broaching associated with surf riding, the International Maritime Organization (IMO decided to develop new physics-based stability criteria to be added to the 2008 Intact Stability Code [1]. They comprised two levels of vulnerability criteria based on simplified physical models with a given safety margin and combined with direct stability assessment using numerical simulation to quantify the probability of stability failure in irregular waves.

The IMO vulnerability criteria were based on surf riding rather than broaching [2]. Surf riding was known to be a precondition for broaching in ship stability failure. Because broaching requires the maneuvering elements to be considered, its use was judged too complicated to be practicable. At the higher-level vulnerability criterion, the probability of surf riding in the North Atlantic was estimated using a global bifurcation analysis and a stochastic wave theory. If the estimated probability was larger than the acceptable safety level, the ship was judged to be vulnerable to surf riding. At its lower level, to avoid explicit use of the surf riding probability, a wave steepness of $1 / 10$ was assumed as the physical upper limit at sea. This allowed the critical Froude number to be determined as 0.3 . These were adopted in IMO operational guidance MSC/ Circ. 707 [3] as amended by MSC.1/Circ. 1228, and the 
vulnerability criteria were agreed in principle by the subcommittee on Ship Design and Construction in 2015 [4].

The issue of direct stability assessment has not yet been fully resolved by the IMO. It requires the quantification of the probability of broaching under maneuvering in irregular waves, and it is unclear whether current methodologies in ship dynamics can evaluate the probability of broaching sufficiently accurately within a practical calculation time. The major problem is that broaching is a nonlinear phenomenon. A mathematical model of broaching has not yet been fully established, and linear superposition techniques are not adequate to apply. In this paper, we attempt to provide positive and rigid answers to this question.

Scientific research on broaching can be traced back to Davidson [5], similar to researches on ship maneuverability, in 1940s. Davidson investigated the directional stability of ships in following waves using a linear sway-yawcoupled model, and treated wave-induced forces as the sum of Froude-Krylov forces and the hydrodynamic lift caused by wave particle velocity. He reported that even directionally stable ships can become directionally unstable on the downslope of waves. Wahab and Swaan [6] pursued this approach further, but using only the Froude Krylov components. Eda [7] proposed a surge-sway-yaw-coupled model for solving the linear stability problem.

In 1982, Motora et al. [8] and Renilson [9] numerically integrated nonlinear equations of surge-sway-yaw motions and concluded that a necessary condition for broaching under surf riding is that the wave-induced yaw moment exceeds the maximum yaw moment supplied by steering. Hamamoto and Akiyoshi [10] and de Kat and Paulling [11] in late 1980s independently developed 6 DOF mathematical models combining strip theory and maneuvering models for capsizing and broaching. Umeda and Renilson [12] developed a 4 DOF mathematical model based on a maneuvering model with roll coupling and linear wave forces under low-encounter frequency assumption. Assuming that wave steepness and maneuvering motions are small, all higher-order terms such as interactions due to maneuvering and waves can be neglected. Umeda and Hashimoto [13] reported that this mathematical model showed qualitative agreement with free-running model experiments using a single-propeller and single-rudder fishing vessel. The International Towing Tank Conference (ITTC) specialist committee on extreme motions and capsizing conducted a benchmark testing study of numerical models with the same model test data and concluded that some numerical approaches can qualitatively predict the occurrence of broaching [14].

To make prediction quantitative, it is necessary to take higher-order terms into account in the mathematical model. Umeda et al. [15] and Hashimoto et al. [16] developed a mathematical model with second-order terms taken into account and derived quantitative prediction for a fishing vessel. Potential flow theories and captive model experiments were used to estimate hydrodynamic forces arising from the interaction between maneuvering and waves; hydrodynamic forces due to the large roll angle, nonlinear wave, and maneuvering forces; and other factors.

However, the establishment of an accurate mathematical model of broaching in regular waves is not the goal of ship dynamics, because the phenomenon itself is nonlinear, making the results sensitive to initial conditions. Techniques based on nonlinear dynamical system theory are required. Such an approach was first applied to surf riding bifurcation of an uncoupled surge motion. Grim [17] explained that the surf riding boundary coincides with the trajectory from an unstable equilibrium of an uncoupled surge model on a wave to another unstable equilibrium. This is a heteroclinic bifurcation in the terminology of nonlinear dynamical system theory. Makov [18] confirmed Grim's theory using phase plane analysis. He found that surf riding of a selfpropelled ship occurs regardless of the initial condition in the phase plane, at the heteroclinic bifurcation. Ananiev [19] obtained an analytically approximated solution by applying a perturbation technique. Spyrou [20] presented an exact analytical solution of the heteroclinic bifurcation of an uncoupled surge model under conditions of quadratic calmwater resistance. In 1990 Kan [21] applied the Melnikov analysis to an uncoupled surge model having a locally linear calm-water resistance curve, and Spyrou [22] did the same with a linear quadratic cubic calm-water resistance curve. Maki et al. [23, 24] provided formulae for calm-water resistance curves as general polynomials for lower and upper surf riding thresholds, and validated them with numerical bifurcation analysis and a free-running model experiment.

Umeda and Renilson [25] extended the nonlinear dynamical system approach from an uncoupled surge model to a coupled surge-sway-yaw model. Spyrou [26, 27] and Umeda [28] numerically obtained a heteroclinic bifurcation for the uncoupled surge model and the coupled surgesway-yaw-roll model with a PD autopilot, respectively. Umeda et al. [29] and Maki et al. [30] applied numerical bifurcation analysis to the coupled model and validated the results using experiments with a fishing vessel model. The results confirmed the existence of distinct initial condition dependence in the occurrence of broaching, but only if the initial condition was set above the periodic states for selfpropelled ships. This allows the initial condition dependence to be disregarded in both numerical simulations and free-running model experiments.

All these studies investigated broaching in single-propeller and single-rudder ships. Since most destroyers and high-speed RoPax ferries have twin propellers and twin rudders, broaching for such vessels must be investigated. Umeda et al. [31] reported that the methodology used for 
single-propeller and single-rudder ships was inapplicable to twin-propeller and twin-rudder ships because a large roll due to broaching could result in the surfacing of a propeller and/or a rudder. Hashimoto et al. [32] used a simplified modification of rudder emergence to model twin-propeller and twin-rudder ships, but a more comprehensive approach is needed. Umeda et al. [33] measured rudder normal forces during broaching in free-running model experiments. The measured rudder normal forces agreed reasonably well with numerical simulation, and the effect of rudder emergence significantly improved prediction accuracy for broaching. Note here that Sadat-Hosseini et al. [34] applied computational fluid dynamics (CFD) to the broaching of a twin-propeller and twin-rudder ship in regular waves, and compared the results with a free-running model experiment. Since this approach requires tremendous computational resources even for regular waves, its direct application to regulations is impractical, so system identification techniques were applied to the CFD results to improve the 6 DOF mathematical model [35].

For regulatory purposes, the danger of broaching in irregular waves also needs to be assessed. Rutgerssen and Ottosson [36] and Motora et al. [8] executed model experiments in irregular waves in a seakeeping and maneuvering basin, and undertook real full-scale measurements at sea. However, the probabilistic aspects of broaching were not addressed. As the probabilistic modeling of broaching in irregular waves is indispensable for practical applications, Umeda [37], in 1990, proposed a theoretical method for estimating surf riding probability in irregular waves, using a deterministic surf riding threshold and the joint probability of local wave heights and wave periods. Umeda et al. [38] extended this methodology to broaching, and successfully validated it using Monte Carlo simulation in a time domain. However, the results have not yet been experimentally confirmed. Themelis and Spyrou [39] proposed a similar methodology without attempting experimental validation.

We have therefore attempted to validate the probabilistic methodology proposed by Umeda et al. [38], by conducting free-running model experiments in irregular waves. The subject ship used was an ONR flared topside vessel, representing a typical high-speed, twin-propeller and twin-rudder ship. The mathematical model was updated for twin-propeller and twin-rudder ships based on our previous literature.

\section{Estimation method for broaching probability}

To estimate the probability of surf riding and/or broaching in irregular waves, one of the authors [37, 38] has proposed a theoretical method based on a combination of deterministic nonlinear ship dynamics and a probabilistic wave theory. Real ocean waves are clearly irregular and can be regarded as a sequence of local sinusoidal waves defined between the zero crossing of water elevation. Each local wave has a wave height and a wavelength. Broaching associated with surf riding normally occurs within one or two waves as the ship is captured, and violently turned, by a wave downslope. Thus, the occurrence of broaching can be estimated from the local wave that the ship encounters and the initial conditions of ship motion. For addressing surf riding probability, both local wave and initial conditions were taken into account [37], while broaching probability was successfully validated using Monte Carlo simulation [38] without considering the effect of initial conditions. In this research, we first attempted to validate the method without taking into account the initial condition effect.

The broaching probability that this paper deals with is the conditional probability when a ship meets a zero-crossing wave. This probability, $P$, can be approximately calculated as the probability of encountering a local wave that causes broaching, so that can be formulated as follows [38]:

$P=\iint_{S(l, s)} p^{*}(l, s) \mathrm{d} l \mathrm{~d} s$,

where $l$ and $s$ represent the local wavelength to ship length ratio and local wave steepness, respectively. The function $p^{*}(l, s)$ is a joint-probability density function of local wavelength to ship length ratio and local wave steepness. $S$ is the region in which a ship suffers broaching in local waves.

In the draft IMO regulation [2], Eq. 1 is represented in the following discretized form:

$P=\sum_{i} \sum_{j} C\left(l_{i}, s_{j}\right) p^{*}\left(l_{i}, s_{j}\right) \Delta l \Delta s$,

where

$C\left(l_{i}, s_{j}\right)=\left\{\begin{array}{lll}1 & \text { if } & \text { broaching occurs } \\ 0 & \text { if } & \text { broaching does not occur }\end{array}\right.$

$C\left(l_{i}, s_{j}\right)$ is obtained using a time-domain numerical simulation in regular waves having the $i$-th wavelength to ship length ratio and the $j$-th wave steepness. If the significant wave height $H_{1 / 3}$ and the mean wave period $T_{O 1}$ are known, a joint-probability density function $p^{*}\left(l_{i}, s_{j}\right)$ for the $i$-th local wavelength to ship length ratio and the $j$-th local wave steepness can be calculated by applying LonguetHiggins' theory [40], as follows:

$$
\begin{aligned}
p^{*}\left(l_{i}, s_{j}\right)= & \frac{4 \sqrt{g}}{\pi v} \frac{L^{5 / 2} T_{01}}{\left(H_{1 / 3}\right)^{3}} s_{j}^{2} l_{i}^{3 / 2}\left(\frac{\sqrt{1+v^{2}}}{1+\sqrt{1+v^{2}}}\right) \\
& \times \exp \left[-2\left(\frac{L l_{i} s_{j}}{H_{1 / 3}}\right)^{2}\left\{1+\frac{1}{v^{2}}\left(1-\sqrt{\frac{g T_{01}^{2}}{2 \pi l_{i} L}}\right)^{2}\right\}\right],
\end{aligned}
$$


where $v(=0.4256)$ is the band parameter for a PiersonMoskowitz spectrum. This is based on the wave envelope theory and has been reasonably well validated with field measurement data.

For determining $S$ or $C$, we used a coupled surge-swayyaw-roll time-domain simulation model in regular waves with an autopilot and then counted the number of occurrences of broaching in the time series obtained. In this process, we needed a criterion to judge whether broaching had occurred. Since broaching is known to mariners as the loss of straight run despite maximum steering efforts, we mathematically simulated this situation using the following criteria [41]:

$\delta=\delta_{\max }, \quad r<0, \quad \dot{r}<0$

or

$\delta=-\delta_{\max }, \quad r>0, \quad \dot{r}>0$,

where $r$ is yaw angular velocity and $\delta$ is the rudder angle. Here, we regarded applying the maximum rudder deflection $\delta_{\max }$ as the maximum steering effort. If the ship yaw angular velocity increases in the opposite direction, this can regarded as broaching. This criterion was used in both model experiments and numerical simulations.

To obtain reliable values of broaching probability, the broaching region $S$ should be defined as accurately as possible, making validation of the time-domain numerical simulation in regular waves indispensable. This will be discussed in the following chapters.

\section{Configuration of the ONR flare topside vessel}

As noted, an ONR flare topside vessel was used as the subject ship. While Hashimoto et al. [32] used the ONR tumblehome topside vessel, the ONR flare topside vessel can be used to represent conventional high-speed monohull ships, as it has twin propellers and twin rudders. A body plan of the subject ship is shown in Fig. 1 and the details of the ship are given in the "Appendix".

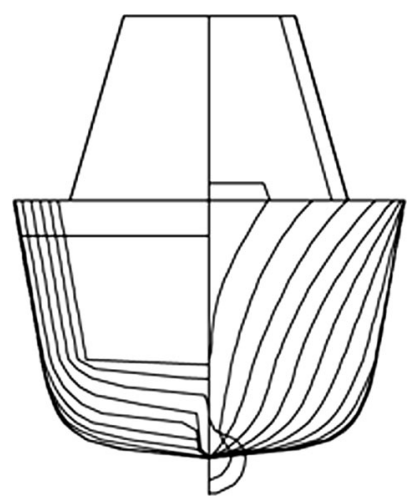

Fig. 1 Body plan of the ONR flare topside vessel
For the model experiments, a ship model with a scale of $1 / 46.60$ was used.

\section{Time-domain numerical simulation model}

\subsection{Mathematical model}

To understand the broaching phenomenon in regular waves, a numerical simulation model based on a coupled surge-sway-yaw-roll maneuvering model with linear wave force and nonlinear restoring variations was used, following Umeda and Hashimoto [42]. Maneuvering, roll damping, and propulsion coefficients were determined using conventional model tests, such as CMT in calm water. Linear wave force was estimated by applying the slender body theory with very low encounter frequencies [43].

Since ships running in following and stern-quartering waves at high forward speeds have low encounter frequencies, a maneuvering-based mathematical model of surge-sway-yaw-roll motion was developed with linear wave-induced forces and a PD autopilot to simulate the broaching associated with surf riding. This is referred to as the "original model." Based on the original model, we developed a mathematical model to predict broaching of twin-propeller and twin-rudder ships running in following and stern-quartering waves. The wave steepness was assumed to be much smaller than one. Drift angle and yaw angular velocity, normalized for a ship length and a forward speed, and rudder angle were also regarded as small because they are induced by waves. The interaction terms of these elements could therefore be disregarded in a firstorder approximation, and hence the maneuvering coefficients did not depend on waves. Roll angle could not be treated as negligible because it is an essential element in predicting a capsize. Propeller thrust, which can be represented by constant linear and quadratic terms of advanced coefficient, could also not be treated as negligible because it includes terms that are proportional to wave steepness. Side force induced by propellers operating in non-axial inflow was neglected, because drift motion during broaching is of minor significance. Based on these assumptions, higher-order terms of heel-induced hydrodynamic forces, wave effect on roll-restoring moment, and wave effect on propeller thrust were taken into account in the mathematical model. As the original model was developed for ships with a single propeller and a single rudder, it was extended to ships with twin propellers and twin rudders following Lee et al. [44] and Furukawa et al. [45]. Propeller thrust and rudder force were presumed to be proportional to the submerged surface area of the propellers and rudders. Both rudders underwent the same 

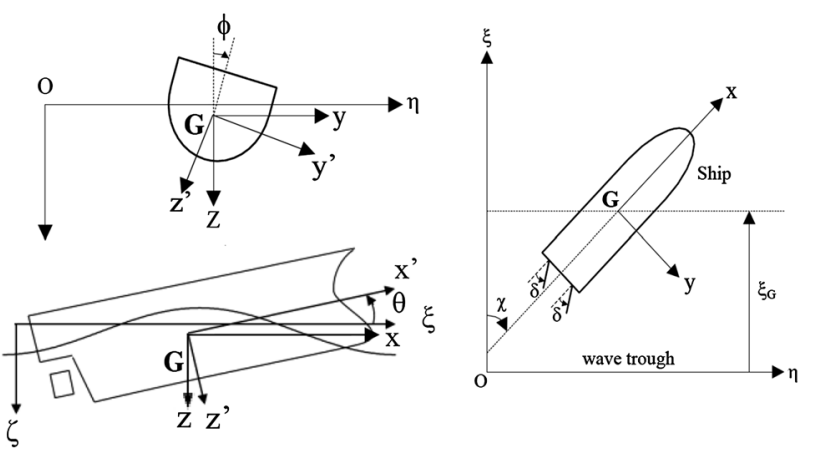

Fig. 2 Coordinate systems

deflection, following the proportional control of the autopilot. Since the wave particle velocity at each propeller position was taken into account as the change in inflow velocity when estimating thrust variation, the turning moment produced by the difference in thrust of the two propellers could be calculated.

The coordinate systems are shown in Fig. 2. A spacefixed coordinate system $O-\xi \eta \zeta$ has its origin at a wave
Based on the coordinate systems, the state vector $\mathbf{x}$ and control vector $\mathbf{b}$ of the system are defined as follows:

$\mathbf{x}=\left(x_{1}, x_{2}, \ldots, x_{8}\right)^{\mathrm{T}}=\left(\xi_{G} / \lambda, u, v, \chi, r, \varphi, p, \delta\right)^{\mathrm{T}}$,

$\mathbf{b}=\left(n, \chi_{C}\right)^{\mathrm{T}}$.

The dynamical system can be represented by the following state equation:

$\dot{\mathbf{x}}=\mathbf{F}(\mathbf{x} ; \mathbf{b})=\left\{f_{1}(\mathbf{x} ; \mathbf{b}), f_{2}(\mathbf{x} ; \mathbf{b}), \ldots, f_{8}(\mathbf{x} ; \mathbf{b})\right\}^{\mathrm{T}}$,

where

$$
\begin{aligned}
f_{1}(\mathbf{x} ; \mathbf{b})= & (u \cos \chi-v \sin \chi-c) / \lambda, \\
f_{2}(\mathbf{x} ; \mathbf{b})= & \left\{T\left(\xi_{G}, \zeta_{G}, u, \varphi, \theta, \chi, t ; n\right)-R(u)+X_{W}\left(\xi_{G}, \chi, t\right) .\right. \\
& \left.+X_{R}\left(\xi_{G} / \lambda, \zeta_{G}, u, \varphi, \theta, \chi, \delta ; n\right)\right\} /\left(m+m_{x}\right)
\end{aligned},
$$

$f_{3}(\mathbf{x} ; \mathbf{b})=\left\{\begin{array}{l}Y_{v}(u) v+Y_{r}(u) r+Y_{v v v}(u) v^{3}+Y_{v v r}(u) v^{2} r+Y_{v r r}(u) v r^{2}+Y_{r r r}(u) r^{3} \\ +Y_{\varphi}(u) \varphi+Y_{R}\left(\xi_{G} / \lambda, \zeta_{G}, u, \varphi, \theta, \chi, \delta ; n\right)+Y_{W}\left(\xi_{G}, u, \chi, t\right)-\left(m+m_{x}\right) u r\end{array}\right\} /\left(m+m_{y}\right)$,

trough. A body-fixed system $G-x^{\prime} y^{\prime} z^{\prime}$ has its origin at the center of gravity of the ship. A horizontal body $G-x y z$

$$
f_{4}(\mathbf{x} ; \mathbf{b})=r
$$
coordinate system [46] also has its origin at the center of gravity and does not rotate around the $x$-axis and $y$-axis.

The space-fixed coordinate system and the body-fixed system have the following relationship:

$$
\left(\begin{array}{l}
x \\
y \\
z
\end{array}\right)=\left(\begin{array}{ccc}
\cos \theta & \sin \varphi \sin \theta & \cos \varphi \sin \theta \\
0 & \cos \varphi & -\sin \varphi \\
-\sin \theta & \sin \varphi \cos \theta & \cos \varphi \cos \theta
\end{array}\right)\left(\begin{array}{l}
x^{\prime} \\
y^{\prime} \\
z^{\prime}
\end{array}\right)
$$

$$
\left(\begin{array}{l}
x^{\prime} \\
y^{\prime} \\
z^{\prime}
\end{array}\right)=\left(\begin{array}{ccc}
\cos \theta \cos \chi & \cos \theta \sin \chi & -\sin \theta \\
\sin \varphi \sin \theta \cos \chi-\cos \varphi \sin \chi & \sin \varphi \sin \theta \sin \chi+\cos \varphi \cos \chi & \sin \varphi \cos \theta \\
\cos \varphi \sin \theta \cos \chi+\sin \varphi \sin \chi & \cos \varphi \sin \theta \sin \chi-\sin \varphi \cos \chi & \cos \varphi \cos \theta
\end{array}\right)\left(\begin{array}{c}
\xi-\xi_{G} \\
\eta-\eta_{G} \\
\zeta-\zeta_{G}
\end{array}\right) .
$$


$f_{5}(\mathbf{x} ; \mathbf{b})=\left\{\begin{array}{c}N_{v}(u) v+N_{r}(u) r+N_{v v v}(u) v^{3}+N_{v v r}(u) v^{2} r+N_{v r r}(u) v r^{2}+N_{r r r}(u) r^{3} \\ +N_{\varphi}(u) \varphi+N_{R}\left(\xi_{G} / \lambda, \zeta_{G}, u, \varphi, \theta, \chi, \delta ; n\right)+N_{W}\left(\xi_{G}, \chi, u, t\right)+N_{T}\end{array}\right\} /\left(I_{z z}+J_{z z}\right)$,

$f_{6}(\mathbf{x} ; \mathbf{b})=p$,

$f_{7}(\mathbf{x} ; \mathbf{b})=\left\{\begin{array}{r}K_{v}(u) v+K_{r}(u) r+K_{v v v}(u) v^{3}+K_{v v r}(u) v^{2} r+K_{v r r}(u) v r^{2}+K_{r r r}(u) r^{3} \\ +K_{\varphi}(u) \varphi+K_{R}\left(\xi_{G} / \lambda, \zeta_{G}, u, \varphi, \theta, \chi, \delta ; n\right)+K_{W}\left(\xi_{G}, \chi, u, t\right) \\ +K_{\dot{\varphi}}(u, p)-m g G Z\left(\xi_{G}, \varphi, t\right)-\left(m+m_{x}\right) u r-m_{y} \dot{v}_{z_{H}}\end{array}\right\} /\left(I_{x x}+J_{x x}\right)$,

$f_{8}(\mathbf{x} ; \mathbf{b})=\left\{-\delta-K_{P}\left(\chi-\chi_{C}\right)-K_{P} T_{D} r\right\} / T_{E}$.

The expression of each term in the state equation can be found in "Appendix".

\subsection{Validation of the calculation model of wave- induced force}

Wave-induced force as the sum of the Froude-Krylov force and the hydrodynamic lift forces acting on the hull and the rudders due to wave particle velocity were modeled as follows: [43]

$$
\begin{aligned}
& X_{W}\left(\xi_{G} / \lambda, \chi\right)=-\alpha \rho g \zeta_{a} k \cos \chi \\
& \int_{A E}^{F E} C_{1}(x) S(x) \mathrm{e}^{-k d(x) / 2} \sin k\left(\xi_{G}+x \cos \chi\right) \mathrm{d} x \\
& Y_{W}\left(\xi_{G} / \lambda, u, \chi\right)=\rho g \zeta_{a} k \sin \chi \\
& \quad \int_{A E}^{F E} C_{1}(x) S(x) \mathrm{e}^{-k d(x) / 2} \sin k\left(\xi_{G}+x \cos \chi\right) \mathrm{d} x \\
& \quad-\zeta_{a} \omega u \sin \chi\left[\rho S_{y}(x) \mathrm{e}^{-k d(x) / 2} \cos k\left(\xi_{G}+x \cos \chi\right)\right]_{A E}^{F E} \\
& N_{W}\left(\xi_{G} / \lambda, u, \chi\right)=\rho g \zeta_{a} k \sin \chi \\
& \quad{ }^{F E} C_{1}(x) S(x) \mathrm{e}^{-k d(x) / 2} x \sin k\left(\xi_{G}+x \cos \chi\right) \mathrm{d} x \\
& { }_{A E}{ }^{F E} \\
& +\zeta_{a} \omega u \sin \chi \int_{A E} \rho S_{y}(x) \mathrm{e}^{-k d(x) / 2} \cos k\left(\xi_{G}+x \cos \chi\right) \mathrm{d} x \\
& -\zeta_{a} \omega u \sin \chi\left[\rho S_{y}(x) \mathrm{e}^{-k d(x) / 2} x \cos k\left(\xi_{G}+x \cos \chi\right)\right]_{A E}^{F E}
\end{aligned}
$$

$$
\begin{aligned}
& K_{W}\left(\xi_{G} / \lambda, u, \chi\right)=\rho g \zeta_{a} k \sin \chi \\
& \quad \int_{A E}^{F E} C_{1}(x) \frac{B(x)}{2}\{d(x)\}^{2} \mathrm{e}^{-k d(x) / 2} \sin k\left(\xi_{G}+x \cos \chi\right) d x \\
& \quad-\rho g \zeta_{a} k^{2} \sin \chi \int_{A E}^{F E} C_{4}(x)\{d(x)\}^{3} \mathrm{e}^{-k d(x) / 2} \sin k\left(\xi_{G}+x \cos \chi\right) d x \\
& \quad-\zeta_{a} \omega u \sin \chi\left[\rho S_{y} l_{n}(x) \mathrm{e}^{-k d(x) / 2} \cos k\left(\xi_{G}+x \cos \chi\right)\right]_{A E}^{F E} \\
& \quad+Y_{w}\left(\xi_{G} / \lambda, u, \chi\right) \cdot \overline{O G}, \\
& C_{1}=\frac{\sin (k \sin \chi \cdot B(x) / 2)}{k \sin \chi \cdot B(x) / 2} \\
& C_{4}=\{k \sin \chi \cdot B(x) / 2\}^{-3} \\
& \quad[2 \sin \{k \sin \chi \cdot B(x) / 2\}-k \sin \chi \cdot B(x) \cos \{k \sin \chi \cdot B(x) / 2\}] .
\end{aligned}
$$

The empirical correction factor for diffraction effect $\alpha$ $(=0.92)$ was used only for surge [47].

For the validation of this model, a captive model test and calculation was conducted with the subject ship model in regular waves. Here, the model was free in heave and pitch. The wave-induced surge and sway forces and yaw and roll moments were measured with a dynamometer. The wave steepness was 0.025 , the wavelength to ship length ratio was 1.25 , the Froude number was 0.31 , and the heading angle from wave direction, $\chi$, was $30^{\circ}$. Obliquely towing the model without propellers was realized by combining an $X-Y$ towing carriage with a turntable.

Here, wave-induced force was normalized as follows:

$$
X_{W}^{\prime}, Y_{W}^{\prime}=X_{W}, Y_{W} /\left(\frac{H W}{\lambda}\right),
$$



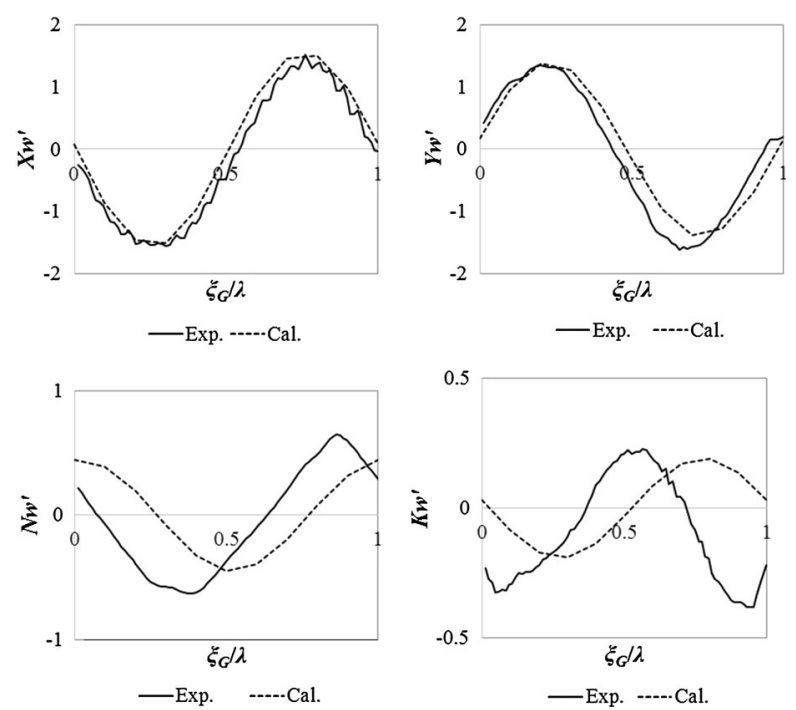

Fig. 3 Comparison of wave-induced surge and sway forces and yaw and roll moments for the ship in regular waves. Here, the wave steepness was 0.025 , the wavelength to ship length ratio 1.25 , the Froude number 0.31 , and the heading angle from wave direction, $\chi$, $30^{\circ}$

$N_{W}^{\prime}=N_{W} /\left(\frac{H W L}{\lambda}\right)$,

$K_{W}^{\prime}=K_{W} /\left(\frac{H W B}{\lambda}\right)$.

As Fig. 3 shows, the results of the calculation of wave-induced yaw moment do not agree with the experimental results. This discrepancy has been noted by many researchers [48, 49] and has been attributed to the linear slender body with or without free surfaces. The discrepancy between the slender body theory and the captive experiment that was found in the present study can be attributed to complicated vortex shedding. In the linear slender body theory, the wave-induced force on each section is integrated along the longitudinal axis. The vortex is assumed to be shed only at the aft end, although in reality this could be done at the separation point of the three-dimensional boundary layer on the hull surface. In the numerical calculation described here, the authors corrected the amplitude and the phase of waveinduced yaw moment, $N_{W}{ }^{\prime}$, to be fitted with the captive model experiment as shown in Fig. 4, i.e., $N_{W}^{\prime}\left(\xi_{G} / \lambda, u, \chi\right)=1.58 N_{W 0}^{\prime}\left(\xi_{G} / \lambda+0.15, u, \chi\right)$, where $N_{W 0}{ }^{\prime}$ means the value calculated by Eq. 21. In future work, the physical background to this empirical correction, for the same vessel, will be quantitatively analyzed using a CFD calculation.

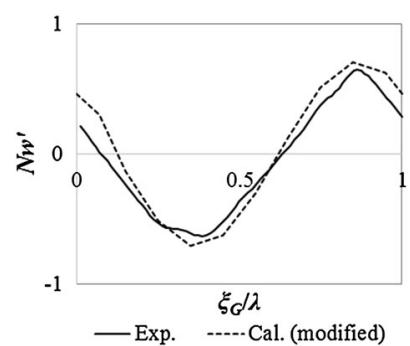

Fig. 4 Correction of the calculation results for wave-induced yaw moment

\section{Free-running model experiment}

To validate the time-domain simulation in regular waves and the theoretical estimation method of broaching probability, free-running model experiments were carried out for the subject ship in a seakeeping and maneuvering basin of the National Research Institute of Fisheries Engineering. The experimental procedure for stern-quartering waves was based on the ITTC-recommended procedure for an intact stability model test [50]. First, the ship model was secured with a guide rope near a wave maker, which then began to generate waves. A radio operator used an onboard system to increase the propeller revolutions up to a specified level and to initiate automatic directional control. After the generated wave trains had propagated far enough, the guide rope was disconnected and the ship began running automatically in following and stern-quartering waves, while attempting to maintain the specified propeller rate and the autopilot course. Throughout this research, the specified propeller rate was given by the nominal Froude number, which is equivalent to the Froude number when the ship is running in otherwise calm water with that propeller rate.

The proportional autopilot was controlled by a computer and a fiber-optic gyro with a rudder gain of 3.0. The roll angle, pitch angle, yaw angle, rudder angle, and propeller rate were recorded by an onboard computer. The water surface elevation was measured with a servo-needle-type wave probe attached to the towing carriage of the basin near the wave maker.

The position of the center of ship gravity $\left(\xi_{G}, \eta_{G}, \zeta_{G}\right)$ on the space-fixed coordinate system was measured instantaneously with a total station system consisting of a theodolite and two prisms attached to the model (Fig. 5). The theodolite emitted light at $20 \mathrm{~Hz}$ and followed the prisms by measuring the phase of light reflected by the prisms. This allowed the estimation of the instantaneous position of the prisms, $\left(\xi_{P}, \eta_{P}, \zeta_{P}\right)$, on the space-fixed coordinate system. By combining this with roll angle, pitch angle, and yaw angle, the instantaneous position of the 


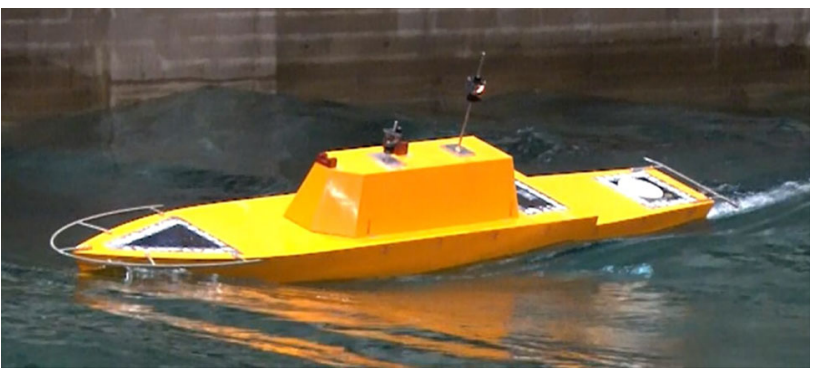

Fig. 5 Photograph of the ship model of ONR flare topside vessel during the experiment

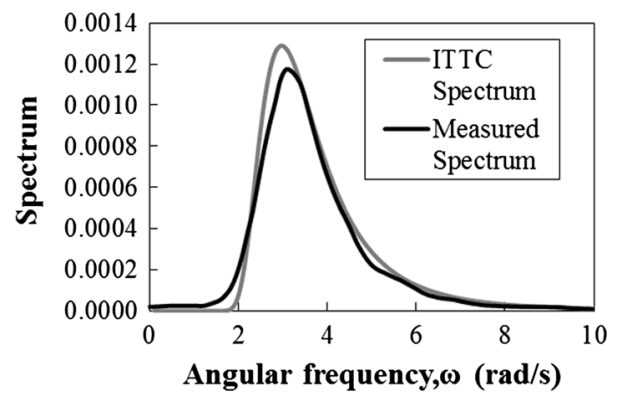

Fig. 6 ITTC spectrum and the measured spectrum during experiments. Here, the significant wave height is $0.207 \mathrm{~m}$ and the zerocrossing mean wave period is $1.627 \mathrm{~s}$. This wave was used for freerunning model experiments described in Sect. 6.2

center of ship gravity could be obtained by Eqs. 6 and 7 [33].

To generate long-crested irregular waves, the ITTC spectrum was specified and then the inverse Fourier transformation with random phases was used for the wave signals. Four hundred wave frequencies were sampled with non-equal increments. The incident wave spectrum estimated with the measured wave records and the fast Fourier transformation agreed closely with the specified spectrum, as shown in Fig. 6.

\section{Results and discussion}

\subsection{Evaluation of the time-domain numerical simulation for ships in regular waves}

Figure 7 compares the time history of the free-running model experiment and the time-domain numerical simulation. The wave steepness was 0.06 , the wavelength to ship length ratio was 1.25 , the nominal Froude number was 0.43 , the autopilot course was $-15^{\circ}$, and the autopilot proportional gain was 3.0. In the experimental results, the ship started to yaw in the opposite direction to the
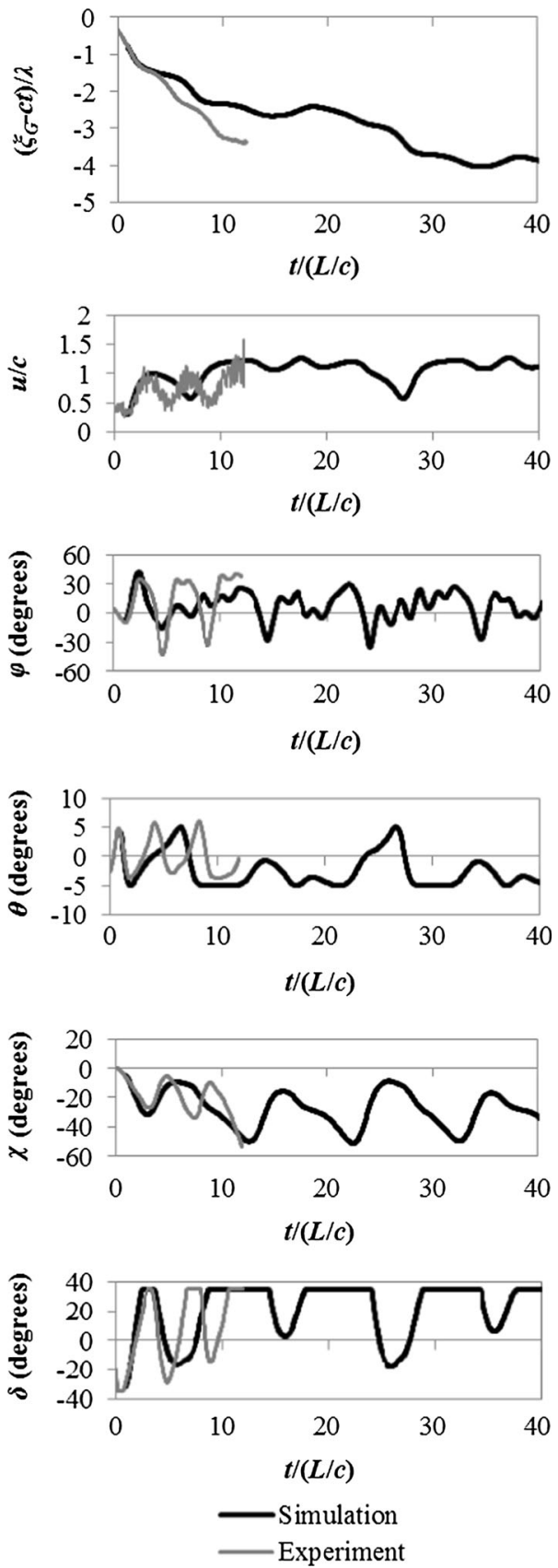

Fig. 7 Comparison of the experiment and the simulation in time series for the ship in regular waves. Here, the wave steepness was 0.06 , the wavelength to ship length ratio was 1.25 , the nominal Froude number was 0.43 , the autopilot course was $-15^{\circ}$, and the autopilot proportional gain was 3.0

maximum rudder angle, satisfying our definition of broaching. The numerical simulation results therefore reproduced the broaching phenomenon accurately. The maximum roll angle was around $40^{\circ}$. The time-domain simulation results modeled the free-running model experiment well at this stage. After the large roll due to 


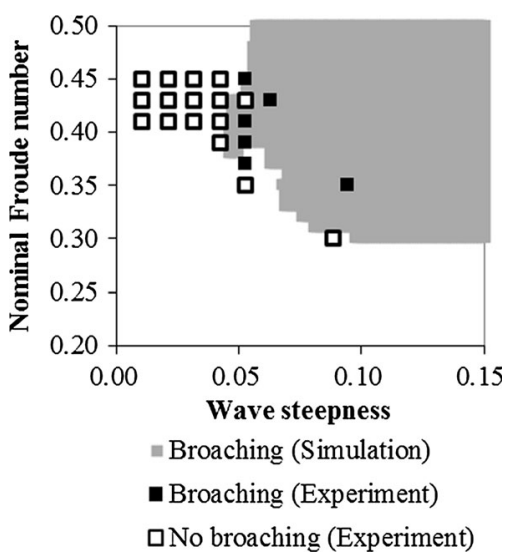

Fig. 8 Comparison of the experiment and simulation in broaching region for the ship in regular waves. Here, the wavelength to ship length ratio is 1.25

broaching, the ship model was overtaken by the wave crest. At this stage, the numerical simulation failed to accurately reproduce the speed reduction, and the simulated ship was more slowly overtaken by the wave crest. Thus, some discrepancy in phase was found between the experiment and the simulation. However, in simple terms of the prediction of broaching, the numerical model performed adequately.

We conducted several free-running model experiments in regular waves with a wavelength to ship length ratio of 1.25. Figure 8 compares the broaching region in the timedomain numerical simulations with the experimental results. The same criteria for broaching were applied, and the comparison was presented at full scale. The experimental results matched those obtained by simulation, both for broaching within the broaching region and nonbroaching outside the broaching region or at its border. Thus, the time-domain simulation model was strongly validated.

\subsection{Evaluation of the theoretical estimation of broaching probability when the ship meets an encounter wave in irregular waves}

To test the theoretical estimation of broaching probability when the ship meets an encounter wave, free-running model experiments were conducted with irregular waves. The experimental procedure is shown in Sect. 5, but for irregular waves. In the free-running model experiments, the significant wave height was $0.207 \mathrm{~m}$, the zero-crossing mean wave period was $1.627 \mathrm{~s}$, the autopilot course was $-15^{\circ}$, the autopilot proportional gain was 3.0 , and the
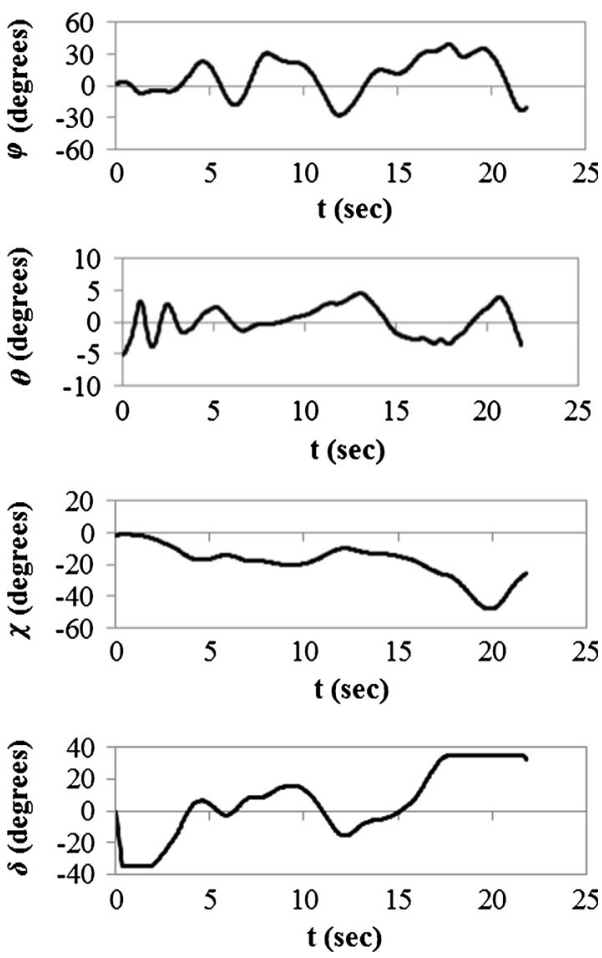

Fig. 9 Example of time records of measured broaching in freerunning model experiment in irregular waves

nominal Froude number was 0.44 . In total, 50 realizations were conducted with different random wave phases. During the 50 realizations, the ship model encountered 104 waves and broaching occurred 9 times. Thus, the simple estimate of broaching probability when the ship meets an encounter wave was 0.0865 . Since the occurrence of broaching is binomial, $95 \%$ confidence interval of the theoretical broaching probability was obtained using the $\mathrm{F}$ distribution. An example of the time records of broaching measured in free-running model experiments in irregular waves is shown in Fig. 9 in model scale. While $t$ is between 17.55 and $18.75 \mathrm{~s}$, despite the maximum rudder deflection, yaw angular velocity develops in the opposite direction. Thus, we can regard it as broaching in irregular waves. Comparing it with broaching in regular waves such as in Fig. 7, the behavior leading to broaching is more complicated due to wave irregularity.

Broaching probability was calculated theoretically as shown in Sect. 2. Figure 10 shows the regions of broaching associated with surf riding in regular waves. In the calculation, we first estimated the zone for surf riding using Melnikov analysis [23] and then executed the time-domain simulation for broaching within the surf riding zone. The obtained zone is represented by $S$ in Eq. 1. Figure 11 


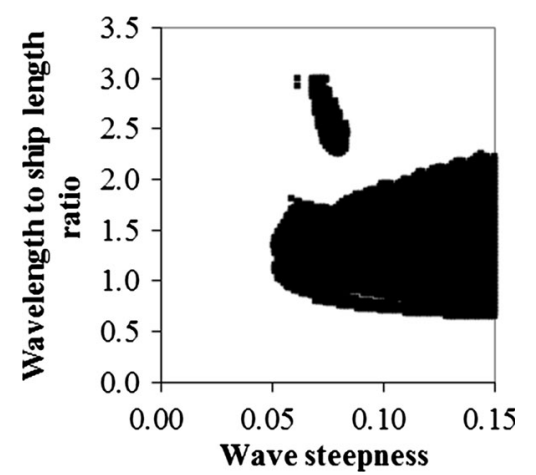

Fig. 10 Calculated broaching regions in regular waves of various wave steepness and wavelength. The nominal Froude number used here is 0.44 . The black dot indicates a case of broaching

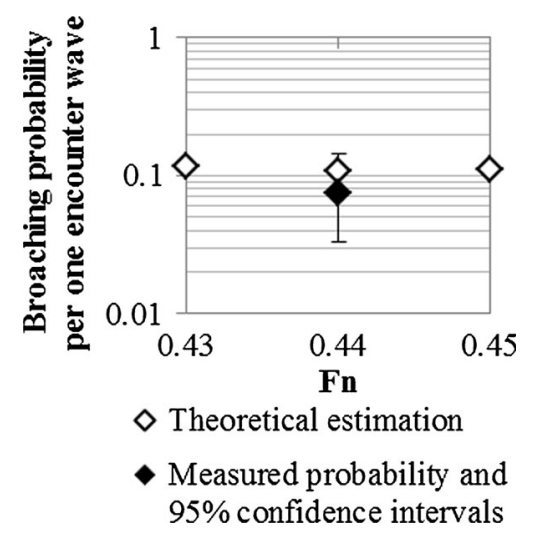

Fig. 11 Comparison of broaching probability between model experiments and numerical simulations for the ship in irregular waves. Here, the significant wave height was $0.207 \mathrm{~m}$, the zero-crossing mean wave period $1.627 \mathrm{~s}$, the autopilot course $-15^{\circ}$, and the autopilot proportional gain 3.0

compares the broaching probability obtained from the theoretical estimation based on Eq. 1 and that obtained from the experimental result. The theoretically calculated broaching probability was within the $95 \%$ confidence interval of the simple estimate from the experimental findings.

\subsection{Evaluation of broaching danger in actual seas}

With this numerical simulation and the theoretical estimation, the broaching probability when the ship meets an encounter wave can be calculated as shown in Fig. 12. Table 1 gives the Beaufort scale and the relevant wave height and wave period applied. The relationship between the Beaufort number and the significant wave height, $H_{1 / 3}$,

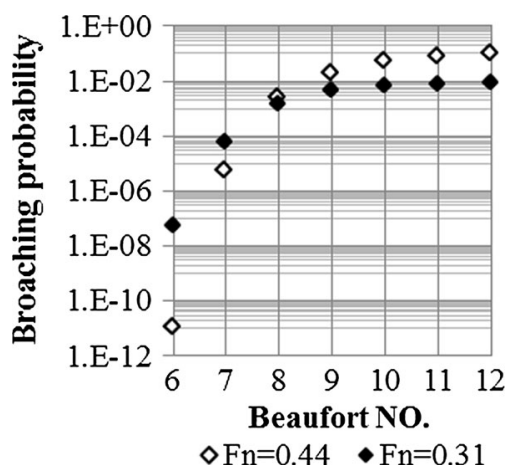

Fig. 12 Broaching probability theoretically obtained for the ship in irregular waves as a function of the Beaufort scale with 0.44 and 0.31 of nominal Froude number

is specified by the World Meteorological Organization (WMO). The mean wave period, $T_{01}$, is calculated as follows:

$T_{01}=3.86 \sqrt{H_{1 / 3}}$,

where $\bar{c}$ and $\bar{\lambda}$ are the wave celerity and the wavelength of the sinusoidal wave whose mean wave period is equal to $T_{01}$. They are calculated as follows:

$\bar{c}=\frac{g T_{01}}{2 \pi}$,

$\bar{\lambda}=\frac{g T_{01}^{2}}{2 \pi}$.

At sea, and when the Beaufort number is smaller, the estimated broaching probability for a ship with a nominal Froude number of 0.44 is lower than that for the one with a nominal Froude number of 0.31 . This is because the ship with a nominal Froude number of 0.44 moves much faster than the relevant waves, and the ship is not so easily surf ridden.

\section{Conclusions}

To validate a theoretical method proposed by one of the authors [37, 38], using a deterministic broaching region and stochastic wave theory, we conducted free-running model experiments of a typical twin-propeller and twinrudder ship in irregular waves. The broaching probability calculated by the theoretical method was within the $95 \%$ confidence interval. We conclude that the theoretical prediction method proposed by Umeda et al. [38] is also applicable to twin-propeller and twin-rudder ships. 
Table 1 Relationships among Beaufort number, significant wave height, and representative wavelength

\begin{tabular}{lllllllll}
\hline Beaufort no. & 5 & 6 & 7 & 8 & 9 & 10 & 11 & 12 \\
$H_{1 / 3}(\mathrm{~m})$ & 2 & 3 & 4 & 5.5 & 7 & 9 & 11.5 & 14 \\
$T_{01}(\mathrm{~s})$ & 5.5 & 6.7 & 7.7 & 9.1 & 10.2 & 11.6 & 13.1 & 14.1 \\
$\bar{\lambda}(\mathrm{m})$ & 47 & 70 & 93 & 130 & 162 & 210 & 267 & 310 \\
$\bar{c} / \sqrt{g L}$ & 0.22 & 0.27 & 0.31 & 0.37 & 0.41 & 0.47 & 0.53 & 0.57 \\
\hline
\end{tabular}

An empirical correction needed to be made for the wave-induced yaw moment found in the captive model experiment. In future research, the physical basis for this empirical correction will be explored using CFD.

Acknowledgments This work was supported by the US Office of Naval Research Global Grant No. N62909-13-1-N257 under the administration of Dr. Woei-Min Lin and a Grant-in Aid for Scientific Research from the Japan Society for Promotion of Science (JSPS KAKENHI Grant Number 15H02327). It was partly carried out as a research activity of Goal-based Stability Criteria Project of Japan Ship Technology Research Association in the fiscal years of 2014-2015 funded by the Nippon Foundation. The authors appreciate Dr. Daisuke Terada, Messrs. Masahiro Sakai and Takaya Miyoshi for their effective assistance in the experiment. The authors would like to thank Enago (http://www.enago.jp) for the English language review.

Open Access This article is distributed under the terms of the Creative Commons Attribution 4.0 International License (http://crea tivecommons.org/licenses/by/4.0/), which permits unrestricted use, distribution, and reproduction in any medium, provided you give appropriate credit to the original author(s) and the source, provide a link to the Creative Commons license, and indicate if changes were made.

\section{Appendix}

The used propulsion and maneuvering models are based on conventional methods such the Maneuvering Modeling Group (MMG) model [51], but adapted for twin propellers and twin rudders and their emersion [33]. To allow readers to reproduce the results, all models and the system parameters used are provided here. The principal particulars and some parameters are shown in Table 2. The length between perpendiculars is defined in this paper as the longitudinal distance between the stem and the rudder shafts. Taking into account the propeller emersion, the propeller thrust and yaw moment due to twin propeller and the hull resistance in calm water are modeled as follows:

$$
\begin{aligned}
T= & \left(1-t_{p}\right) \rho n^{2} D_{p}^{4} K_{T}(J) \cdot\left(\frac{S_{P}+S_{S}}{S_{\infty}}\right), \\
N_{T}= & -\left(1-t_{p}\right) \rho n^{2} D_{p}^{4} K_{T}(J) \\
& \times\left(\frac{S_{P}}{S_{\infty}} y_{P P}+\frac{S_{S}}{S_{\infty}} y_{P S}\right), \\
R= & \frac{1}{2} \rho S_{F} u^{2} C_{T}\left(\frac{u}{\sqrt{L g}}\right),
\end{aligned}
$$

Table 2 Principal particulars and system parameters of the ONR flare

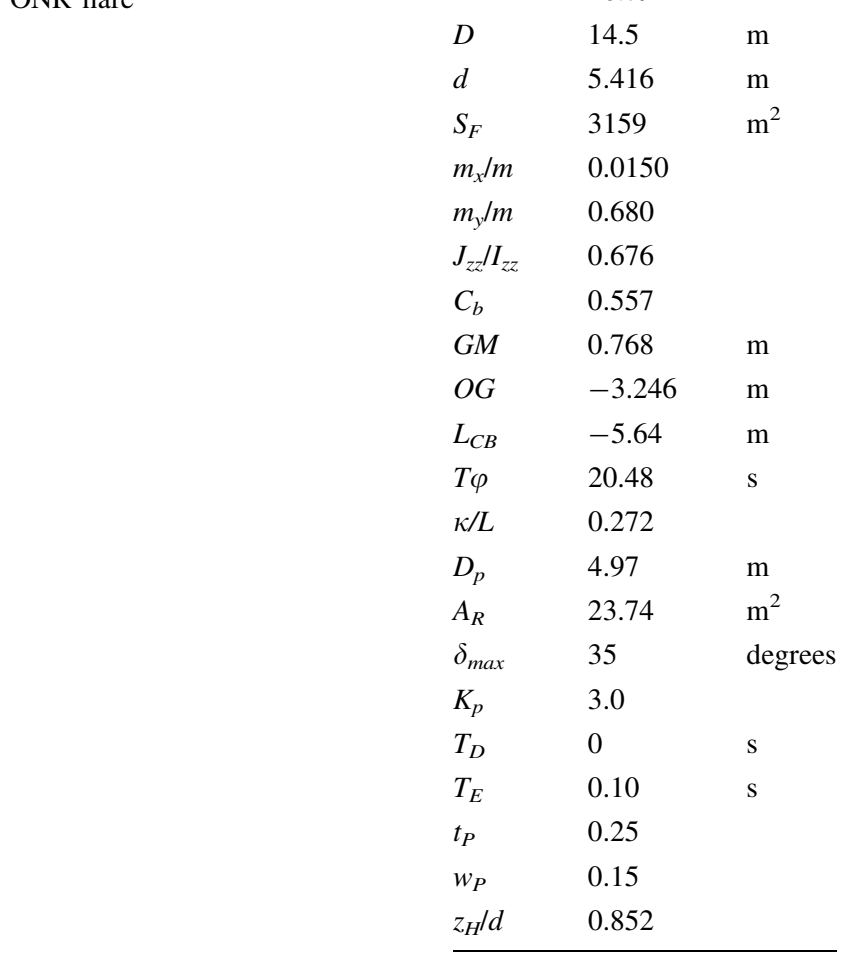

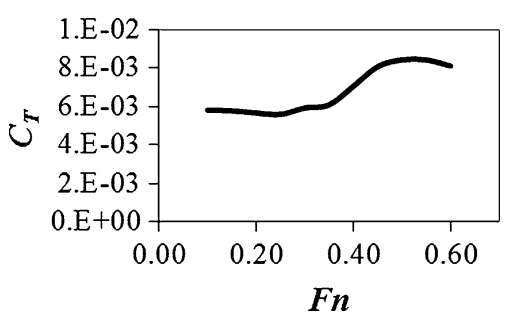

Fig. 13 Calm-water resistance of the ship measured in resistance test

where

$$
\begin{aligned}
& J=\frac{\left(1-w_{P}\right) u}{n D_{P}}, \\
& S_{P}=\int_{\zeta_{P P}-\zeta_{W r}}^{\frac{D_{P}}{2}} 2 \sqrt{\left(D_{P} / 2\right)^{2}-y^{2}} \mathrm{~d} y, \\
& S_{S}=\int_{\zeta_{P S}-\zeta_{W r}}^{\frac{D_{P}}{2}} 2 \sqrt{\left(D_{P} / 2\right)^{2}-y^{2}} \mathrm{~d} y .
\end{aligned}
$$




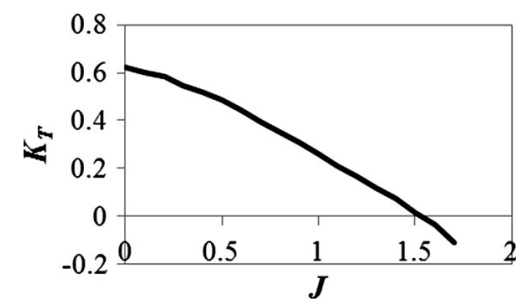

Fig. 14 Propeller thrust measured in propeller open test. Topside vessel at the full scale

Here, the total resistance coefficient and the propeller thrust coefficient measured in conventional model tests are shown in Figs. 13 and 14, respectively. The relative wave elevation was estimated with incident wave elevation, and heave and pitch motions were calculated as those in static balance in a wave.

With propeller emergence taken into account, the rudder-induced forces and moments in waves are modeled as follows:

$$
\begin{aligned}
& X_{R}\left(\xi_{G} / \lambda, \zeta_{G}, u, \varphi, \theta, \chi, \delta ; n\right) \\
& =-\left(1-t_{R}\right) F_{N} \sin \delta, \\
& Y_{R}\left(\xi_{G} / \lambda, \zeta_{G}, u, \varphi, \theta, \chi, \delta ; n\right) \\
& =-\left(1+a_{H}\right) F_{N} \cos \delta, \\
& N_{R}\left(\xi_{G} / \lambda, \zeta_{G}, u, \varphi, \theta, \chi, \delta ; n\right) \\
& =-\left(x_{R}+a_{H} x_{H R}\right) F_{N} \cos \delta, \\
& K_{R}\left(\xi_{G} / \lambda, \zeta_{G}, u, \varphi, \theta, \chi, \delta ; n\right) \\
& =\left(z_{R}+a_{H} z_{H R}\right) F_{N} \cos \delta,
\end{aligned}
$$

where

$$
\begin{aligned}
F_{N}= & \frac{1}{2} \rho\left(A_{R P}+A_{R S}\right) u_{R}^{2} f_{\alpha} \sin \alpha_{R}, \\
u_{R}= & \varepsilon\left(1-w_{P}\right) u \\
& \times \sqrt{\eta^{\prime}\left\{1+\kappa\left(\sqrt{1+\frac{8 K_{T}(J)}{\pi J^{2}}}-1\right)\right\}^{2}+1-\eta^{\prime},} \\
\alpha_{R}= & \delta-\frac{v_{R P}}{u}-\gamma \frac{U}{u_{R}}\left(\beta-l_{R}^{\prime} r^{\prime}\right), \\
f_{\alpha}= & \frac{6.13 \Lambda_{R}}{\Lambda_{R}+2.25}, \\
\eta^{\prime}= & \frac{A_{R 1}}{A_{R}} .
\end{aligned}
$$

$A_{R P}$ and $A_{R S}$ are the submerged areas of the port and starboard rudders, respectively. $A_{R 1}$ is the rudder area inside the propeller race. The parameters included in Eq. 37-43 were obtained with a conventional captive model test using the circular motion technique in Table 3.
Table 3 System parameters for rudder forces

\begin{tabular}{ll}
\hline $1-t_{R}$ & 0.323 \\
$1+a_{H}$ & 0.843 \\
$x_{R}+a_{H} x_{H R}$ & -57.4 \\
$z_{R}+a_{H} z_{H R}$ & 5.37 \\
$\kappa$ & 0.647 \\
$\varepsilon$ & 0.932 \\
$\gamma$ & 0.472 \\
$l_{R}{ }^{\prime}$ & -0.709 \\
\hline
\end{tabular}

Table 4 Maneuvering coefficients

\begin{tabular}{lccc}
\hline$Y_{v}{ }^{\prime}$ & -0.380 & $N_{v}{ }^{\prime}$ & -0.0714 \\
$Y_{r}{ }^{\prime}$ & 0.0427 & $N_{r}{ }^{\prime}$ & -0.0752 \\
$Y_{v v v}{ }^{\prime}$ & -1.41 & $N_{v v v}{ }^{\prime}$ & -0.434 \\
$Y_{v v r}{ }^{\prime}$ & -0.541 & $N_{v v r}{ }^{\prime}$ & -0.542 \\
$Y_{v r r}{ }^{\prime}$ & -0.717 & $N_{v r r}{ }^{\prime}$ & -0.0709 \\
$Y_{r r r}{ }^{\prime}$ & 0.0789 & $N_{r r r}{ }^{\prime}$ & -0.00148 \\
\hline$F_{n}$ & $Y_{\varphi}{ }^{\prime}$ & $N_{\varphi}{ }^{\prime}$ & $K_{\varphi}{ }^{\prime}$ \\
\hline 0.15 & 0.00354 & -0.00524 & -0.0191 \\
0.20 & 0.0360 & -0.00519 & -0.0465 \\
0.25 & -0.000747 & -0.00464 & -0.0160 \\
0.30 & 0.00204 & -0.00341 & -0.0111 \\
0.35 & -0.0213 & -0.00296 & -0.00636 \\
0.40 & -0.0311 & -0.00277 & 0.000348 \\
0.45 & -0.0485 & -0.00415 & 0.0134 \\
0.50 & -0.0361 & -0.00381 & -0.00701 \\
0.55 & -0.0488 & -0.00455 & 0.00636 \\
0.60 & -0.0626 & -0.00107 & 0.0191 \\
\hline
\end{tabular}

The rudder inflow velocity due to incident waves was ignored as discussed from a hydrodynamic viewpoint in Umeda et al. [33].

Each maneuvering coefficient was determined in captive model experiments using the circular motion technique in Table 4.

$Y_{v}^{\prime}=Y_{v} /\left(\frac{\rho}{2} L d U\right)$,

$Y_{r}^{\prime}=Y_{r} /\left(\frac{\rho}{2} L^{2} d U\right)$,

$Y_{v v v}^{\prime}=Y_{v v v} /\left(\frac{\rho}{2} L d / U\right)$,

$Y_{v v r}^{\prime}=Y_{v v r} /\left(\frac{\rho}{2} L^{2} d / U\right)$,

$Y_{v r r}^{\prime}=Y_{v r r} /\left(\frac{\rho}{2} L^{3} d / U\right)$,

$Y_{r r r}^{\prime}=Y_{r r r} /\left(\frac{\rho}{2} L^{4} d / U\right)$,

$N_{v}^{\prime}=N_{v} /\left(\frac{\rho}{2} L^{2} d U\right)$ 


$$
\begin{aligned}
& N_{r}^{\prime}=N_{r} /\left(\frac{\rho}{2} L^{3} d U\right) \\
& N_{v v v}^{\prime}=N_{v v v} /\left(\frac{\rho}{2} L^{2} d / U\right), \\
& N_{v v r}^{\prime}=N_{v v r} /\left(\frac{\rho}{2} L^{3} d / U\right), \\
& N_{v r r}^{\prime}=N_{v r r} /\left(\frac{\rho}{2} L^{4} d / U\right), \\
& N_{r r r}^{\prime}=N_{r r r} /\left(\frac{\rho}{2} L^{5} d / U\right), \\
& Y_{\varphi}^{\prime}=Y_{\varphi} /\left(\frac{\rho}{2} L d U^{2}\right) \\
& N_{\varphi}^{\prime}=N_{\varphi} /\left(\frac{\rho}{2} L^{2} d U^{2}\right) \\
& K_{\varphi}^{\prime}=K_{\varphi} /\left(\frac{\rho}{2} L d^{2} U^{2}\right) .
\end{aligned}
$$

The roll restoring variation due to waves is calculated by integrating the incident wave pressure up to the incident wave surface with Grim's effective wave concept. Here, the radiation and diffraction waves are ignored and the heave and pitch are calculated as a static balance because of low encounter frequency.

The roll damping moment $K_{\dot{\varphi}}(u, p)$ is calculated as follows:

$K_{\dot{\varphi}}(u, p)=2 \alpha\left(I_{x x}+J_{x x}\right) p+\beta\left(I_{x x}+J_{x x}\right) p \cdot|p|$.

Here, the coefficients $\alpha$ and $\beta$ were obtained with the roll decay model experiments as follows:

$\alpha=\frac{2 a}{T_{\varphi}}$

$\beta=\frac{3}{4} b\left(\frac{180}{\pi}\right)$,

where

$a=0.1574+0.855 F n$,

$b=0.751$.

\section{References}

1. IMO (2009) International code on intact stability. 2008 (2009 version), IMO, London

2. IMO (2015) Report of the working group (part 1), SDC 2/WP.4, Annex 3, pp 1-5

3. IMO (1995) Guidance to the master for avoiding dangerous situation in following and quartering seas, MSC/Circ. 707

4. Japan (2014) Information collected by the correspondence group on intact stability, SDC 2/INF.10. Annex 32, pp 1-5

5. Davidson KSM (1948) A note on the steering of ships in following seas. In: Proceedings of international congress of applied mechanics. London, pp 554-556

6. Wahab R, Swaan WA (1964) Coursekeeping and broaching of ships in following seas. J Ship Res 7:1-15
7. Eda H (1972) Directional stability and control of ships in waves. J Ship Res 16:205-218

8. Motora S, Fujino M, Fuwa T (1982) On the mechanism of broaching-to phenomena. In: Proceedings of the 2nd international conference on stability and ocean vehicles. The Society of Naval Architects of Japan, Tokyo, pp 535-550

9. Renilson MR (1982) An investigation into the factors affecting the likelihood of broaching-to in following seas. In: Proceedings of the 2nd international conference on stability and ocean vehicles. The Society of Naval Architects of Japan, Tokyo, pp 551-564

10. Hamamoto M, Akiyoshi T (1988) Study on ship motion and capsizing in following seas (first report). J Soc Naval Arch Jpn 163:185-192

11. de Kat JO, Paulling JR (1989) The simulation of ship motions and capsizing in severe seas. Trans Soc Naval Arch Mar Eng 97:139-168

12. Umeda N, Renilson MR (1994) Broaching of a fishing vessel in following and quartering seas. In: Proceedings of the 5th international conference on stability of ships and ocean vehicles, vol 3. Florida Institute, Melbourne, pp 115-132

13. Umeda N, Hashimoto $H$ (2002) Qualitative aspects of nonlinear ship motions in following and quartering seas with high forward velocity. J Mar Sci Technol 6:111-121

14. Umeda N, Renilson MR (2001) Benchmark testing of numerical prediction on capsizing of intact ships in following and quartering seas. In: Proceedings of the 5th international workshop on stability and operational safety of ships. University of Trieste, pp 6.1.1-6.1.10

15. Umeda N, Hashimoto H, Matsuda A (2003) Broaching prediction in the light of an enhanced mathematical model with higher order terms taken into account. J Mar Sci Technol 7:145-155

16. Hashimoto H, Umeda N, Matsuda A (2004) Importance of several nonlinear factors on broaching prediction. J Mar Sci Technol 9:80-93

17. Grim O (1951) Das Schiff in von Achtern Auflaufender See. Jahrbuch Schiffbautechnishe Gesellscaft, 4 Band, pp 264-287

18. Makov Y (1969) Some results of theoretical analysis of surfriding in following seas. Trans Krylov Soc 126:124-128 (in Russian)

19. Ananiev DM (1966) On surf-riding in following seas. Trans Krylov Soc 13:169-176 (in Russian)

20. Spyrou KJ (2001) Exact analytical solutions for asymmetric surging and surf-riding. In: Proceedings of the 5th international workshop on stability and operational safety of ships. University of Trieste, pp 4.4.1-4.4.3

21. Kan M (1990) A guideline to avoid the dangerous surf-riding. In: Proceedings of the 4th international conference on stability of ships and ocean vehicles. University Federico II of Naples, Naples, pp 90-97

22. Spyrou KJ (2006) Asymmetric surging of ships in following seas and its repercussion for safety. Nonlinear Dyn 43:149-172

23. Maki A, Umeda N, Renilson MR, Ueta T (2010) Analytical formulae for predicting the surf-riding threshold for a ship in following seas. J Mar Sci Technol 15:218-229

24. Maki A, Umeda N, Renilson MR, Ueta T (2014) Analytical methods to predict the surf-riding threshold and the waveblocking threshold in astern seas. J Mar Sci Technol 19:415-424

25. Umeda N, Renilson MR (1992) Broaching-a dynamic analysis of yaw behaviour of a vessel in a following sea. In: Wilson PA (ed) Manoeuvring and control of marine craft. Computational Mechanics Publications, Southampton, pp 533-543

26. Spyrou KJ (1995) Surf-riding, yaw instability and large heeling of ships in following/quartering waves. Schiffstechnik 42:103-112

27. Spyrou KJ (1996) Dynamic instability in quartering waves: the behaviour of a ship during broaching. J Ship Res 40:46-59 
28. Umeda N (1999) Nonlinear dynamics on ship capsizing due to broaching in following and quartering seas. J Mar Sci Technol 4:16-26

29. Umeda N, Hori M, Hashimoto H (2007) Theoretical prediction of broaching in the light of local and global bifurcation analysis. Int Shipbuild Progr 54:269-281

30. Maki A, Umeda N (2008) Numerical prediction of the surf-riding threshold of a ship in stern quartering waves in the light of bifurcation theory. J Mar Sci Technol 14:80-88

31. Umeda N, Yamamura S, Matsuda A, Maki A, Hashimoto $\mathrm{H}$ (2008) Model experiments on extreme motions of a wavepiercing tumblehome vessel in following and quartering waves. J Jpn Soc Naval Arch Ocean Eng 8:123-129

32. Hashimoto H, Umeda N, Matsuda A (2011) Broaching prediction of a wave-piercing tumblehome vessel with twin screws and twin rudders. J Mar Sci Technol 16:448-461

33. Umeda N, Furukawa T, Matsuda, A and Usada, S (2014) Rudder normal force during broaching of a ship in stern quartering waves. In: Proceedings of the 30th ONR symposium on naval hydrodynamics, Hobart, CD

34. Sadat-Hosseini H, Carrica P, Stern F, Umeda N, Hashimoto H, Yamamura S, Matsuda A (2011) CFD, system-based and EFD study of ship dynamic instability events: surf-riding, periodic motion, and boaching. Ocean Eng 38:88-110

35. Araki M, Sadat-Hosseini H, Sanada Y, Tanimoto K, Umeda N, Stern F (2012) Estimating maneuvering coefficients using system identification methods with experimental, system-based, and CFD fee-running trial data. Ocean Eng 51:63-84

36. Rutgersson O, Ottosson P (1987) Model Tests and computer simulations - an effective combination for investigation of broaching phenomena. Trans Soc Naval Arch Mar Eng 95:263-281

37. Umeda N (1990) Probabilistic study on surf-riding of a ship in irregular following seas. In: Proceedings of the 4th international conference on stability of ships and ocean vehicles. University Federico II of Naples, pp 336-343

38. Umeda N, Shuto M, Maki A (2007) Theoretical prediction of broaching probability for a ship in irregular astern seas. In: Proceedings of the 9th international workshop on stability of ships, GL, 5.1.1-7
39. Themelis N, Spyrou KJ (2007) Probabilistic assessment of ship stability. Trans Soc Naval Arch Mar Eng 115:181-206

40. Longuet-Higgins MS (1983) On the joint distribution of wave periods and amplitudes in a random wave field. Proc R Soc Lond Ser A389:241-258

41. Umeda N, Matsuda A, Takagi M (1999) Model experiment on anti-broaching steering system. J Soc Naval Arch Jpn 185:41-48

42. Umeda N, Hashimoto H (2006) Recent developments of capsizing prediction techniques of intact ships running in waves. In: Proceedings of the 26th ONR symposium on naval hydrodynamics. INSEAN, Rome, CD

43. Umeda N, Yamakoshi Y, Suzuki S (1995) Experimental study for wave forces on a ship running in quartering seas with very low encounter frequency. In: Proceedings of the international symposium on ship safety in a seaway, pp 14.1-18

44. Lee SK, Fujino M, Fukasawa T (1988) A study on the manoeuvring mathematical model for a twin-propeller twin-rudder ship. J Naval Arch Jpn 163:109-118

45. Furukawa, T, Umeda, N, Matsuda, A, Terada, D, Hashimoto, H, Stern, F, Araki, M, Sadat-Hosseinin, H (2012) Effect of hull form above calm water plane on extreme ship motions in stern quartering waves, In: Proceedings of the 29th ONR symposium on naval hydrodynamics, Gothenburg, CD

46. Hamamoto M, Kim YS (1993) A new coordinate system and the equations describing manoeuvring motion of a ship in waves. J Soc Naval Arch Jpn 173:209-220

47. Ito Y, Umeda N, Kubo H (2014) Hydrodynamic aspects on vulnerability criteria for surf-riding of ships. J Teknolgi Sci Eng 66:127-132

48. Fujino M, Yamasaki K, Ishii Y (1983) On the stability derivatives of a ship travelling in following waves. J Soc Naval Arch Jpn 152:167-179

49. Ohkusu M (1986) Prediction on wave forces on a ship running in following waves with very low encounter frequency. J Soc Naval Arch Jpn 159:129-138

50. ITTC (2008) Recommended procedures, model tests on intact stability, 7.5-02-07-04

51. Yasukawa H, Yoshimura Y (2015) Introduction of MMG standard method for ship manoeuvring predictions. J Mar Sci Technol 20:37-52 